\title{
XXII. Viscosity of solutions
}

\section{R. Hosking}

To cite this article: R. Hosking (1900) XXII. Viscosity of solutions, Philosophical Magazine Series 5, 49:298, 274-286, DOI: 10.1080/14786440009463844

To link to this article: http://dx.doi.org/10.1080/14786440009463844

曲 Published online: 21 Apr 2009.

Submit your article to this journal 준

Q View related articles $₫$

4 Citing articles: 7 View citing articles 준 
When ellipse and circle intersect,

$$
x= \pm 0.58601, \quad z= \pm 0.31945 \text {. }
$$

When ellipse is outside circle,

$$
x= \pm 0 \cdot 60200, \quad y= \pm 0.30250 \text {. }
$$

The real intersections on the axes are

$$
\begin{aligned}
& \nu_{1} x^{4}+v_{2} x^{2}+\nu_{3}=0, \\
& \lambda_{3} z^{4}+2 \mu_{3} z^{2}+\nu_{3}=0 .
\end{aligned}
$$

When ellipse and circle intersect,

$$
x= \pm 0.58619, \quad z=0.44278 \text {. }
$$

When ellipse is outside circle,

$$
x= \pm 0 \cdot 60257, y=0.43628 \text {. }
$$

As the difference in lengths of axes of the crystals has been much exaggerated in the diagrams, only the relative positions of these points and lines are shown.

A word should be said regarding the physical interpretation of the parts of the locus hitherto omitted. A supposititions case of refraction, which cannot be realized, may be given to explain the existence of the dotted branches of the curve. If a source of light were situated at the origin of coordinates, emitting an ordinary and extraordinary ray in opposite directions, then the locus which would give coincidence of direction to these rays is the dottel curves indicated.

I have not been able to interpret the presence of the singular points on the axes. When the intersections on the axes are singular points they always lie inside loth the ellipse and the circle. The two tangents to the ellipse and circle, which are the wave-fronts of the rays of light, are consequently imaginary. It seems, then, as if the rays also must be imaginary.

XXII. Viscosity of Solutions. By R. HosEInG, Kernot Research Scholar in the University of Melbourne*.

T $\mathrm{T}$ is evident that, in the immediate future, the study of the 1 viscosity of liquids is destined to prove as helpful in the investigation of the molecular kinetics of liquids as the corresponding study of gaseous viscosity has been found to be in the kinetic theory of gases.

Already a large amount of work on the viscosity of liquids has been published, but much of the pioneer work has been

* Communicated by Mr. IV. Sutherland on behalf of Prof. 
superseded by the recent careful measurements of Thorpэ and Rodger (Phil. Trans. 1894).

The object of the present experimantal investigation is to bring the data for some typical solutions up to at least the standard of completeness attained by Thorpe and Rodger for the commoner liquids ; for it is probable that in the next important advance in the theory of solutions, viscosity will have a considerable share. The solutions chosen for study were those of $\mathrm{NaCl} 1$ per cent., 5 p $\uplus$ r cent., 10 per cent., and 20 per cent., representing typical electrolytic solutions; and of cane-sugar 1 per cent., 5 per cent., 10 per cent., 20 per cent., and 40 per cent., representing typical non-electrolytic solutions. Absolute values of the viscosity were obtained over a range of temperature from $0^{\circ}$ to $90^{\circ} \mathrm{C}$.

To ascertain whether the viscosities of these solutions had been determined to the desired degree of accuracy, a preliminary study of the viscosity of water over the sume range of temperature was undertaken; and as it was found that the results were in accord with the best determinations hitherto made, such as those of Poiseuille, Sprung, Slotte, and Thorpe and Rodger, it was concluded that the viscosities of solutions obtained with the same apparatus could be taken to possess the desired degree of accuracy.

In the tables containing the data obtained in these experiments, those for water will be given along with the values for solutions.

The method employed was that used by Thorpe and Rodger, the general principles of which are bere stated.

A definite volume of the liquid under observation, under the influence of a definite pressure, flows through a horizontal capillary tube of known dimensions in a certain time, the temperature of the liquid being observed and kept constant during the interval.

The liquid, for the purposes of experiment, was contained in a glass glischrometer, similar to that employed by Thorpe and Rodger, with the difference, however, that the short capillary tube, instead of being sealed to the two limbs, was united to them by means of two indiarubber corks, one at each end of the capillary tube.

The glischrometer was almost completely immersed in a water-bath, which was heated to the desired temperature by gas-flames, and could be maintilined at that temperature by manipulation of a very small jet applied beneath it.

On each vertical limb of the glischrometer two horizontal marks were etched, in the restricted portions above and below the long cylindrical bulbs; the two limbs had been mado 
perfectly similar in size and shape, and so the two marks on either limb were placed symmetrically with regard to the bulb between them, and, when the capillary tube was horizontal, and limbs vertical, the two upper marks were in the same horizontal plane, and likewise the two lower ones.

The volume of liquid employed in the experiments is that which the glischrometer holds when the one meniscus is level with the upper mark in the one limb, and the other meniscus coincides with the lower mark in the other limb. The volume which flows through the capillary, however, is that contained between the two marks on the same limb, diminished by the small quantity which adberes to the sides of the bulb.

The pressure is that due to a reservoir of compressed air, which can be connected to either limb at pleasure, and is measured by an open water-manometer.

The time of flow is measured by a stop-watch, and the temperature of the liquid is that of the bath surrounding it, and is indicated by thermometers graduated to tenths.

\section{Measurement of the Conslants of the Glischrometer.}

These constants are the semi-axes of the capillary, the working length of the capillary, and the working volume of the bulbs, where the working length of the capillary means the measured length together with the Couette correction for the open ends, and the working volume means the quantity of liquid which flows through the capillary in an experiment. These constants are determined before the portions of the glischrometer are united together.

The capillary tube was selected and cut from a much longer piece which had been previously calibrated with extreme care, and of which the mean diameter had been obtained by weighing the mercury which had occupied known lengths in the tube. The mean diameter of the selected portion was deduced. The bore was slightly elliptical, and the ratio of the axes was observed directly under a microscope. From these two series of measurements, the values of the semi-axes were obtained. The length of the capillary was measured directly, the ends having been previously ground perpendicular to the length of the bore.

To obtain the working volume of the bulbs, a suitable capillary tube was attached to the lower extremity of the limb, and the limb filled with water. The pressure was then applied above, and the liquid was driven through at about the same rate as it would be in the ordinary experiments. The discharge from the instant when the meniscus passed the upper 
mark to that when it crossed the lower mark was caught in a weighed flask and immediately weighed.

The only disadvantage of the use of corks instead of making the whole glischrometer of glass and sealing the capillary and limbs together, is that a ring of rubber 8 millim. in mean diameter and 0.5 millim. in width is in contact with the liqnid at each end of the capillary tube; but in the case of aqueous solutions there is nothing to fear in the way of dissolved rubber. By the use of corks, on the other hand, in addition to the fact that the constants of the glischrometer can be evaluated before uniting the limbs and capillary, we have the further advantages that cleaning operations are much facilitated, risk of breakage is diminished, and capillary tubes of different dimensions can readily be substituted if necessary.

The following values were obtained for the constants :-

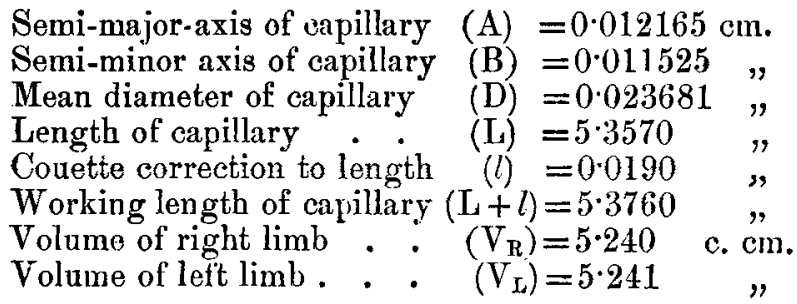

The formula from which the values of the viscosity are found is

$$
\eta=\frac{\pi \mathrm{A}^{3} \mathrm{~B}^{3} \mathrm{G} \rho h \mathrm{~T}}{4 \mathrm{~V}\left(\mathrm{~A}^{2}+\mathrm{B}^{2}\right)(\mathrm{L}+l)}-\frac{\mathrm{A} \mathrm{B} \mathrm{V}}{4 \pi\left(\mathrm{A}^{2}+\mathrm{B}^{2}\right)(\mathrm{L}+l)} \frac{\delta}{\mathrm{T}}(1+2 \beta t) ;
$$

where the second term represents the kinetic-energy correction, and

$\eta$ is the viscosity coefficient,

$G$ is the value of the acceleration due to gravity,

$\rho$ is the density of water in the water-manometer,

$h$ is the height of water in the manometer,

$\mathrm{T}$ is the time taken for volume $\mathrm{V}$ to flow through the capillary under pressure G $\rho h$,

$\delta$ is the density of liquid under observation at the particular temperature; and

$(1+2 \beta t)$ is the correcting term for expansion of the glass, where $\beta$ is the linear coefficient of expansion, and $t$ is the temperature of the experiment.

The formula then becomes

$$
\eta=\alpha \times \rho \times h \times \mathrm{T}-\beta \times \frac{\delta}{\mathrm{T}} \times(1+2 \beta t),
$$

Phil. Mag. S. 5. Vol. 49. No. 298. March 1900. U 
and

$$
\log \alpha=\overline{7} \cdot 4282145 ; \log \beta=\overline{2} \cdot 5880686 .
$$

All the necessary corrections were made to the readings of the stop-watch, the thermometers, and the pressure-gauge. The flow through the capillary tube was in every case linear, and the kinetic-energy correction comparatively small.

Care was taken that the liquid should remain free from dust throughout the whole series of observations. The amount of liquid in the glischrometer was so regulated that at each temperature the volume should be unaltered. The observations were begun at low temperatures in every case; and when the liquid in the glischrometer had reached the next higher temperature, the increase in volume was extracted.

The air-reservoir was a large copper eylinder connected with a pump on the one side, and on the other side with the manometer and two glass three-way taps, by means of rubber tubing and T-pieces. The two taps were united by rubber tubing to the limbs of the glischrometer, one to each, and the liquid in the glischrometer could be driven in either direction by proper adjustment of the taps.

The bath was provided with the necessary taps and syphons for filling and emptying it, and, in addition, for rumning a continuous stream of cold water through the bath for temperatures below the normal.

The glischrometer, thermometer, and syphon-tubes were kept in position by the cover of the bath, through which suitable holes had been bored. Another hole in the cover admitted the shaft of a small propeller for stirring the water of the bath, with power taken from a small water-motor. When the propeller was rotated quickly by this means, a splendid circulation was set up in the bath.

In explanation of the accompanying tables, the following short description of the order of observations may be necessary.

Imagine that the observations are complete at one temperature, and the bath is being heated to the next temperature at which we desire to make a measurement.

When this temperature bas been reached, the stirrer is set in motion and the regulating flame increased to prevent cooling: when the temperature remains practically constant, the liquid is driven into the right limb by turning the left tap to pressure and the right to air : when the meniscus in the left limb has reached the lower mark, the left tap is also turned to air, and the indiarubber from the top of the 
right limb having been just previously removed, the extra quantity of liquid due to expansion is withdrawn by a suitable instrument, the meniscus being made to coincide with the upper mark on the right limb when the meniscus in the left limb coincides with the lower mark on that side. Connexion is again restored between the right limb and the right tap.

The left tap is now for a few seconds turned to pressure, and then the right tap is turned also.

The first reading of the pressure is now taken, and the left tap turned to air. The upper mark in $\mathrm{R}$ (=right side) is observed through a telescopo, and, when the meniscus crosses $i t$, the watch is started. Immediately the first reading of the temperature is made, through another telescope. The first telescope is moved down on its graduated vertical scale to view the lower mark in $R$.

The stop-wateh is stopped at the instant of coincidence, the second reading of the temperature is taken, and the left tap turned to pressure. The second reading of the pressure is now taken. A second set of observations is taken with the liquid flowing in the opposite direction. When this set is complete, the stirrer is stopped, unless the whole set is to be repeated, and the experiment at this particular temperature is at an end.

'The value for the viscosity is determined for each set of readings; and if the temperature has remained unaltered, the mean of the two values is taken as the first absolute valuo at that temperature. A second absolute value is obtained from the third and fourth sets of observations, that is the second complete set: here a complete set represents two ordinary sets-one from right to left, and the other from left to right.

The temperature, however, usually alters slightly during an experiment at a particular temperature; and we may obtain four different readings of the mean temperature and four different values of the viscosity. We have then to reduce these four values to what they would be at the mean of the four temperatures, for which purpose the value of $d \eta / d t$ is obtained from a curve drawn through the points representing the first values of viscosity and temperature in each set, and by means of it the four values are reduced to values at the mean temperature. Then, as before, the mean of the first and second values gives the first mean value, and the mean of the third and fourth the second mean value. The mean of these values is taken as the final mean value. 


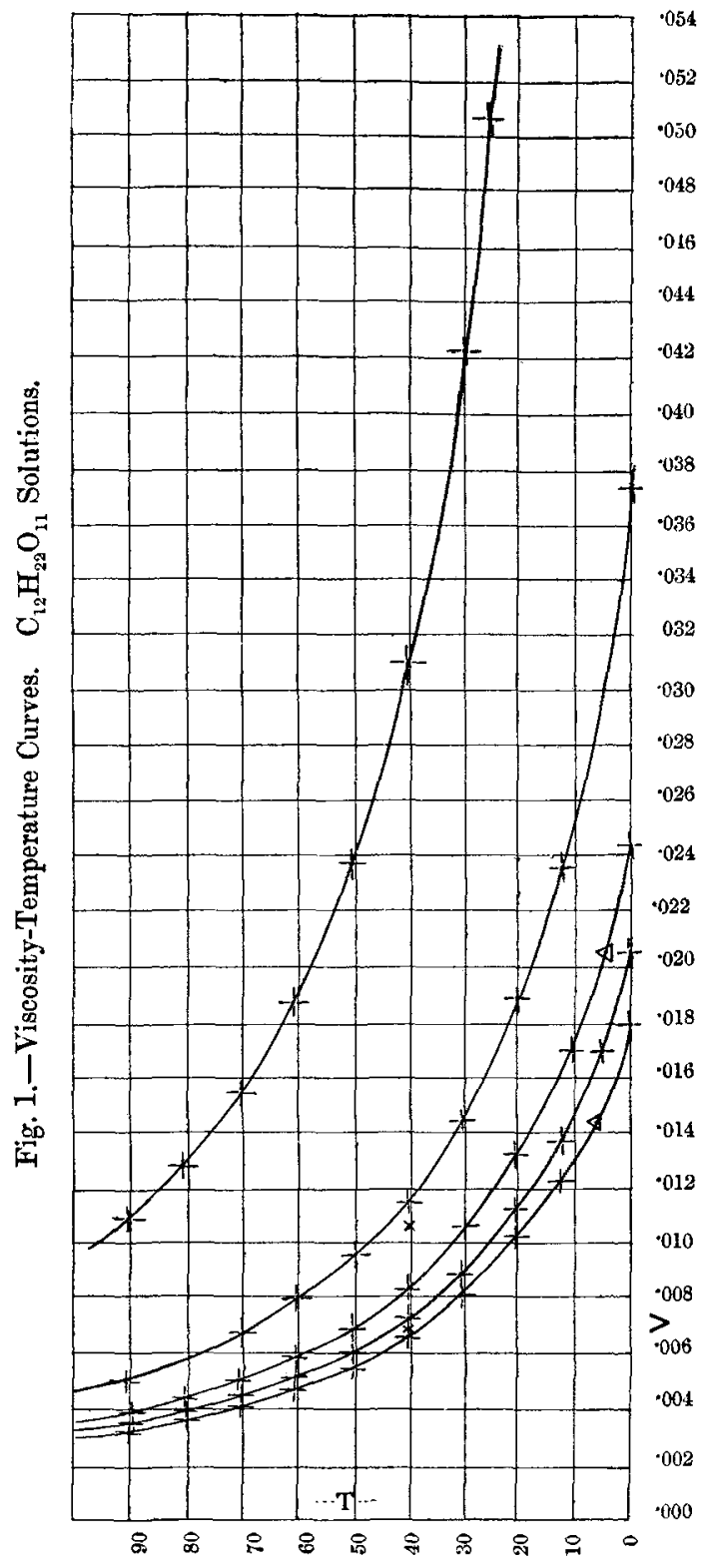


In Table I. will be found typical sets of observations and results caleulated in the case of water at certain temperatures.

The mean pressure only has been given, but the difference between the first and second readings is always slight.

The value of the kinetic-energy correction is also shown in this table, and in the case of water at $90^{\circ}$ it has its greatest relative value.

Fig. 2.-Viscosity-Temperature Curves. $\mathrm{NaCl}$ Solutions.

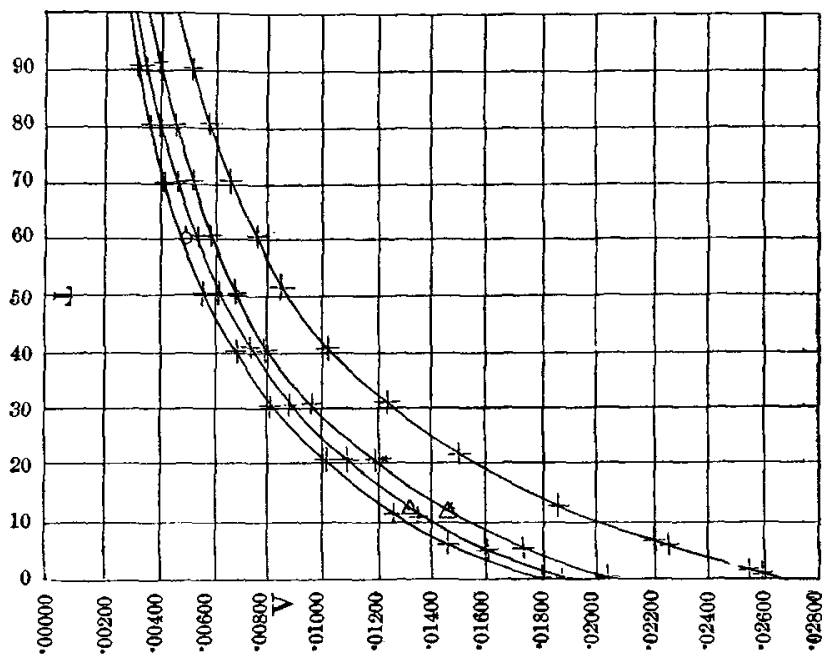

In Table II. the temperature is the mean, and the four values (1), (2), (3), (4) are the reduced values obtained as above.

In Table III. we have the interpolated results for water compared with those determined by other experimenters, whose values are those given by Thorpe and Rodger.

In Table IV. we have produced the final mean values only, except in the case of the 20-per-cent. solution, where in addition we bave shown the first and second mean values.

The NaCl solutions were made from a sample of Schuchardt's "very pure" kindly supplied by Mr. W. P.Wilkinson, analyst, Melbourne.

The densities of these solutions are here given at $15^{\circ} \mathrm{C} .:-$ 20 p. c. $\quad 10$ p.c. $\quad 5$ p.c. 1 p.c. Observed $\ldots \ldots \ldots \ldots \ldots \ldots, 1.1494 \quad 1.0724 \quad 1.0355 \quad 1.0065$ Bender's values (Wied.Ann.xxii.) 1.1497 1.0724 1.0355 - 


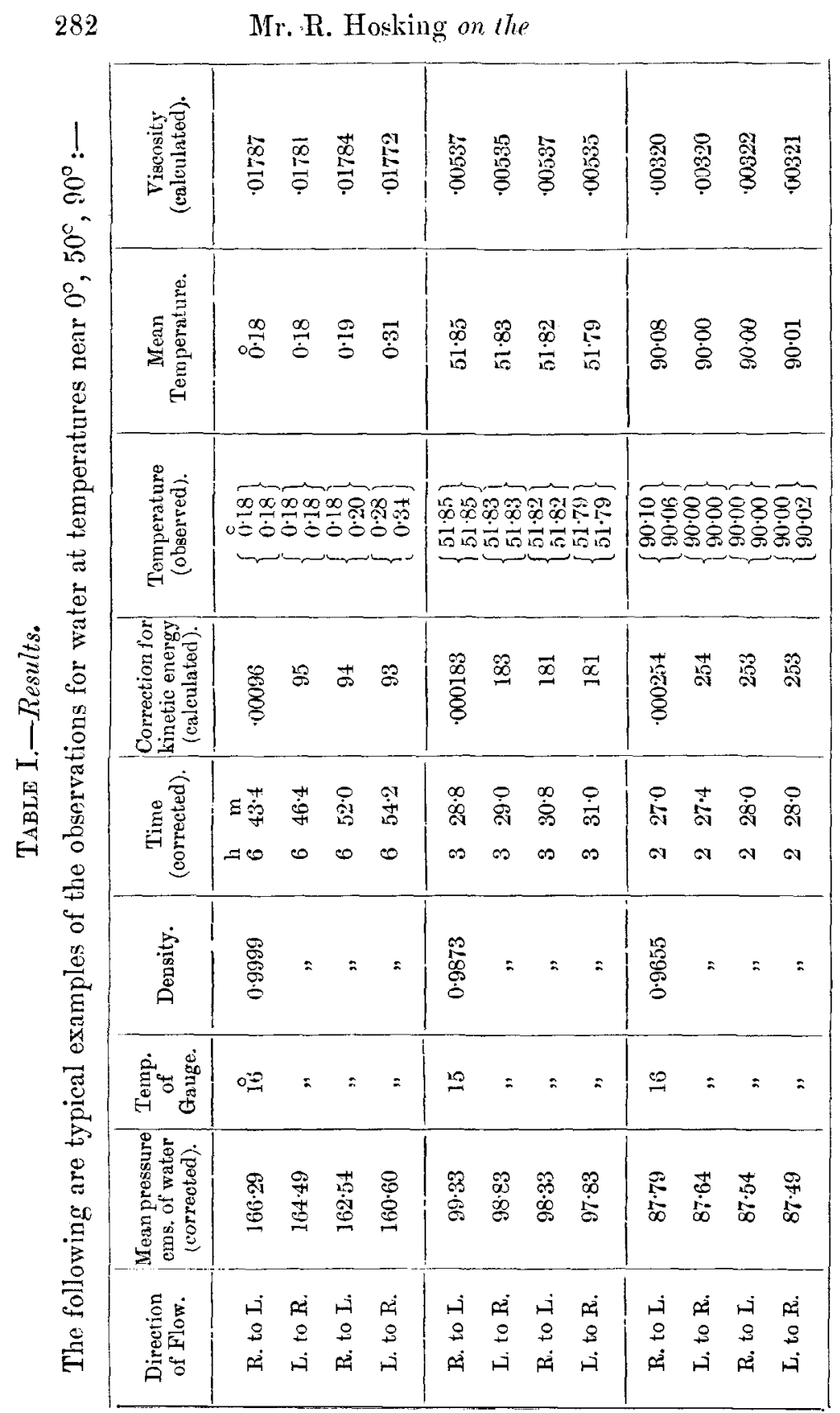


In Table $\mathrm{V}$, we have the interpolated results for $\mathrm{NaCl}$.

In Table VI. the final mean values only, for sugar solutions. The sample of sugar used was supplied by Professor Masson. The densities of the solutions at $17^{c} .5 \mathrm{C}$. are here given:-

p. c. 20 p.c. 10 p.c. 5 p.c. 1 p.c Watt's Dict ............. $1 \cdot 1790 \quad 1.0830 \quad 1.0403 \quad 1.0192 \quad 1.0033$ And iast ed.) $1.1794 \quad 1.0833 \quad 1.0401 \quad 1.0197$

And in Table VII. the interpolated values for sugar solutions are reproduced.

For the purposes of interpolation the results were plotted on a suitably large scale. The results are herewith shown plotted on a smalier scale in figs. $1 \& 2$ (pp. 280, 281). A value of the viscosity at ordinary temperatures was sometimes obtained after the liquid had been heated above $90^{\circ}$, cooled down again, and allowed to remain, in some cases 24 and in others 36 hours, in the glischrometer. These observations are indicated in a different way in the accompanying curves, to the ordinary observations.

TABLe II.-Water.

\begin{tabular}{|c|c|c|c|c|c|}
\hline \multirow[b]{2}{*}{ Temp. } & \multicolumn{5}{|c|}{ Viscosities. } \\
\hline & R. (1) $\mathrm{L}$. & L. to $\mathrm{R}$. & R. to $\mathrm{L}$. & L. to $R$. & Mean. \\
\hline 021 & .01785 & $\cdot 01778$ & .01783 & $\cdot 01778$ & .01781 \\
\hline $2 \cdot 37$ & .01655 & 01653 & .01658 & .01656 & $\begin{array}{r}01656 \\
\end{array}$ \\
\hline 6.53 & .01456 & .01451 & .01455 & .01450 & .01453 \\
\hline 989 & 01316 & .01314 & 013145 & .01314 & .01315 \\
\hline $12 \cdot 44$ & 01227 & .01222 & 01222 & 01220 & 01223 \\
\hline $20 \% 2$ & .00992 & .00990 & .00991 & .0บ990 & .00991 \\
\hline $30 \cdot 78$ & $\cdot 007895$ & .00788 & $\cdot 007885$ & $\cdot 00788$ & $\cdot 007885$ \\
\hline $41 \cdot 74$ & .006385 & .006385 & 00637 & .00638 & .00638 \\
\hline 51.82 & .00537 & .00535 & .00537 & .00534 & .00536 \\
\hline 60.67 & .00467 & .00466 & $\cdot 00468$ & .00467 & .00467 \\
\hline $71 \cdot 58$ & $\{.00400$ & $\cdot 00399$ & .00399 & .00398 & .00399 \\
\hline & $\begin{array}{r}.00401 \\
.00355\end{array}$ & $\begin{array}{l}.00398 \\
.00354\end{array}$ & $\begin{array}{l}.00399 \\
.00356\end{array}$ & $\begin{array}{l}.00398 \\
.00353\end{array}$ & \\
\hline $81 \cdot 19$ & $\left\{\begin{array}{l}00050 \\
.00355\end{array}\right.$ & .00354 & .00355 & -00354 & $\cdot 003545$ \\
\hline $90 \cdot 10$ & $\left\{\begin{array}{l}.003195 \\
.00321\end{array}\right.$ & $\left.\begin{array}{l}.00319 \\
.00321\end{array}\right\}$ & .00320 & .00320 & .00320 \\
\hline
\end{tabular}


TABLe III.-Interpolated Results (Water).

\begin{tabular}{|c|c|c|c|c|c|}
\hline Temp. & $\begin{array}{c}1846 . \\
\text { Poiseuille. }\end{array}$ & $\begin{array}{c}1876 . \\
\text { Sprung. }\end{array}$ & $\begin{array}{l}1883 . \\
\text { Slotte. }\end{array}$ & $\begin{array}{l}1894 . \\
\text { Thorpe \& } \\
\text { Rodger. }\end{array}$ & 1899. \\
\hline $\begin{array}{r}0 \\
5 \\
10 \\
15 \\
20 \\
25 \\
30 \\
35 \\
40 \\
45 \\
50 \\
55 \\
60 \\
65 \\
70 \\
75 \\
80 \\
85 \\
90 \\
95 \\
100\end{array}$ & 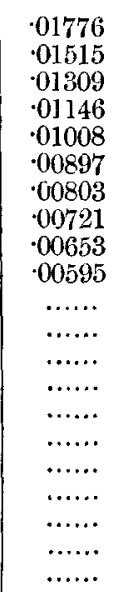 & 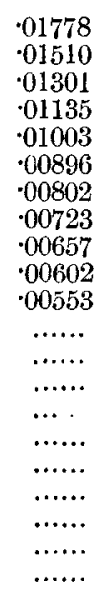 & 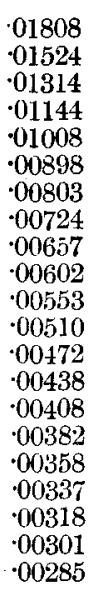 & 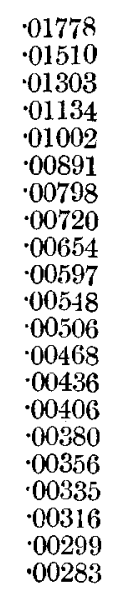 & $\begin{array}{l}\cdot 01794 \\
01520 \\
.01309 \\
.01143 \\
.01009 \\
\cdot 00897 \\
\cdot 00802 \\
\cdot 00724 \\
\cdot 00657 \\
.00601 \\
.00553 \\
\cdot 00510 \\
\cdot 00472 \\
\cdot 00437 \\
\cdot 00407 \\
\cdot 00382 \\
\cdot 00360 \\
.00339 \\
\cdot 00320\end{array}$ \\
\hline
\end{tabular}

TAble IV.-NaCl Solutions.

\begin{tabular}{|c|c|c|c|c|c|c|c|c|c|}
\hline \multirow[b]{2}{*}{ Temp. } & \multicolumn{3}{|c|}{20 per cent. } & \multicolumn{2}{|c|}{10 per cent. } & \multicolumn{2}{|c|}{5 per cent. } & \multicolumn{2}{|c|}{1 per cent. } \\
\hline & $\frac{(1)}{\text { Viscosity }}$ & $\begin{array}{c}(2) \\
\text { Viscosity. }\end{array}$ & $\begin{array}{c}\text { Mean } \\
\text { Viscosity. }\end{array}$ & Temp. & Viscosity & 'Temp. & Viscosity. & Temp. & Viscosity. \\
\hline$\stackrel{\circ}{0} 72$ & $\cdot 02591$ & & 02591 & $0 \cdot 06$ & .02035 & $0 \cdot 00$ & 01861 & 0.00 & .01798 \\
\hline $1 \cdot 24$ & .02547 & & $\cdot 02547$ & & & & & & \\
\hline $5 \cdot 46$ & .02240 & & $\cdot 02: 40$ & $4 \cdot 99$ & .01738 & $4 \cdot 90$ & 01605 & $6 \cdot 39$ & $\cdot 01460$ \\
\hline $5 \cdot 95$ & .02203 & & .02203 & & & & & & \\
\hline $12 \cdot 48$ & 018465 & .01848 & 01847 & $11 \cdot 80$ & .01450 & $10 \cdot 89$ & $\cdot 01357$ & $11 \cdot 76$ & $\cdot 01254$ \\
\hline $21 \cdot 20$ & .01499 & .01498 & .01499 & $20 \cdot 46$ & .01181 & $20 \cdot 22$ & .01078 & $20 \cdot 26$ & .01009 \\
\hline $30 \cdot 69$ & .01221 & .01222 & 01222 & 30.72 & .00947 & $50 \cdot 12$ & .00872 & 3008 & 00809 \\
\hline 40.57 & .01014 & .01013 & 01013 & $40 \cdot 30$ & .00797 & 4086 & .00714 & $40 \cdot 15$ & .00664 \\
\hline $51 \cdot 65$ & .00842 & .00843 & .008425 & 5072 & .00671 & $50 \cdot 19$ & .00614 & 50.42 & $\cdot 005565$ \\
\hline $60 \cdot 65$ & .00736 & .00737 & $\cdot 00736$ & $60 \cdot 67$ & .00584 & $60 \cdot 84$ & .00524 & $60 \cdot 39$ & 00486 \\
\hline $70 \cdot 62$ & 006415 & .00642 & .00642 & $70 \cdot 72$ & .00512 & $70 \cdot 10$ & .00455 & $70 \cdot 10$ & .00416 \\
\hline $80 \cdot 88$ & $\cdot 00566$ & .00565 & $\cdot 00565$ & $80 \cdot 27$ & $\cdot 00452$ & $80 \cdot 25$ & $\cdot 00398$ & $80 \cdot 32$ & .00366 \\
\hline $90 \cdot 60$ & .00504 & .00504 & .00504 & $91 \cdot 30$ & .00396 & 9060 & .003515 & $90 \cdot 24$ & .00324 \\
\hline
\end{tabular}


TABLE V.-Interpolated Results ( $\mathrm{NaCl})$.

\begin{tabular}{|c|c|c|c|c|}
\hline \multirow{2}{*}{ Tenp. } & \multicolumn{4}{|c|}{ Viscosities. } \\
\hline & 1 per cent. & 5 per cent. & 10 per cent. & 20 per cent. \\
\hline i... & $\cdot 01799$ & $\cdot 01862$ & .02041 & .02666 \\
\hline $5 \ldots$ & .01534 & .01600 & .01738 & .02269 \\
\hline $10 \ldots$. & $\cdot 01320$ & .01390 & .01528 & 01968 \\
\hline $15 \quad \ldots \ldots \ldots \ldots$ & 01154 & 01223 & .01345 & .01733 \\
\hline $20 \ldots \ldots \ldots$ & $\cdot 01018$ & .01083 & .01194 & .01540 \\
\hline $25 \ldots$ & .00905 & $\cdot 00973$ & 01066 & $\cdot 01378$ \\
\hline $30 \ldots$ & $\cdot 00810$ & .00876 & .00961 & $\cdot 01239$ \\
\hline $35 \ldots$ & .00731 & .00796 & $\cdot 00875$ & .01124 \\
\hline $40 \ldots$ & $\cdot 00666$ & .00725 & $\cdot 00802$ & $\cdot 01025$ \\
\hline $45 \ldots$ & $\cdot 00609$ & .00666 & $\cdot 00737$ & $\cdot 00939$ \\
\hline $50 \quad \ldots . \ldots \ldots \ldots$ & .00559 & $\cdot 00614$ & .00680 & .00866 \\
\hline $55 \quad \ldots \ldots \ldots \ldots$ & $.005] 9$ & .00569 & $\cdot 00633$ & .00801 \\
\hline $60 \ldots$ & .00481 & 00531 & .00589 & $\cdot 00744$ \\
\hline $65 \ldots$ & $\cdot 00448$ & .00492 & $: 00550$ & .00693 \\
\hline $70 \ldots \ldots \ldots \ldots$ & $00+16$ & $\cdot 00456$ & .00516 & .00649 \\
\hline $75 \quad \ldots \ldots \ldots \ldots$ & .00391 & .00425 & -0i)484 & .00607 \\
\hline $80 \ldots \ldots \ldots$ & .00368 & $\cdot 00399$ & $\cdot 00455$ & $\cdot 00571$ \\
\hline $85 \ldots \ldots \ldots \ldots$ & .00346 & $\cdot 00375$ & .00427 & .00537 \\
\hline $90 \ldots \ldots \ldots$ & .00325 & $\cdot 00355$ & $\cdot 00401$ & .00507 \\
\hline
\end{tabular}

TAble VI.-Sugar Solutions.

\begin{tabular}{|c|c|c|c|c|c|c|c|c|c|}
\hline \multicolumn{2}{|c|}{40 per cent. } & \multicolumn{2}{|c|}{20 per cent. } & \multicolumn{2}{|c|}{10 per cent. } & \multicolumn{2}{|c|}{5 per cent. } & \multicolumn{2}{|c|}{1 per cent. } \\
\hline Temp. & Viscosity & Temp. & Viscosity & Temp & Viscosity & Temp. & Viscosity & Temp. & Viscosity \\
\hline 0.00 & $\cdot 1476$ & $\stackrel{\circ}{0.00}$ & $\cdot 03720$ & 0.00 & .02436 & $0^{\circ} 10$ & .02038 & $0 \cdot 10$ & $\cdot 01801$ \\
\hline 8.87 & .0939 & $5 \cdot 43$ & $\cdot 03002$ & $5 \cdot 10$ & .02042 & $5 \cdot 26$ & .01716 & $7 \cdot 10$ & .01437 \\
\hline $12 \cdot 79$ & .0798 & 13.02 & $\cdot 02351$ & $10 \cdot 42$ & .01722 & $12 \cdot \overline{5} 8$ & .01381 & $13 \cdot 32$ & .01218 \\
\hline $20 \cdot 23$ & .06004 & 20.04 & $\cdot 01910$ & $20 \cdot 17$ & .01322 & $20 \cdot 29$ & .01127 & $20 \cdot 60$ & .01031 \\
\hline 29.98 & .04233 & $30 \cdot 44$ & .01466 & 29.89 & .01041 & $30 \cdot 43$ & .00889 & 3043 & $\cdot 00804$ \\
\hline $40 \cdot 44$ & .03100 & $40 \cdot 31$ & $\cdot 01171$ & $40 \cdot 30$ & .00838 & $40 \cdot 40$ & .00725 & $40 \cdot 18$ & 00667 \\
\hline 50.31 & .02390 & $50 \cdot 30$ & .00952 & $50 \cdot 35$ & .00696 & $50 \cdot 46$ & .00605 & $50 \cdot 13$ & .00554 \\
\hline $60 \cdot 51$ & .01884 & $60 \cdot 20$ & .00797 & $60 \cdot 27$ & .00590 & $60 \cdot 34$ & .00517 & 60.54 & .00470 \\
\hline 7006 & .01550 & $70 \cdot 06$ & .00675 & $70: 36$ & .00509 & $70 \cdot 25$ & .00449 & $70 \cdot 04$ & .00410 \\
\hline $80 \cdot 32$ & $\cdot 01279$ & $80 \cdot 21$ & .00583 & $80 \cdot 31$ & .00446 & $80 \cdot 00$ & .00399 & 80.06 & .003615 \\
\hline $90 \cdot 11$ & $\cdot 01086$ & $90 \cdot 21$ & .00509 & $89 \cdot 78$ & .00390 & $89 \cdot 84$ & .003505 & $90 \cdot 00$ & .00320 \\
\hline
\end{tabular}


TABLE VII.-Interpolated Results $\left(\mathrm{C}_{12} \mathrm{H}_{22} \mathrm{U}_{11}\right)$.

\begin{tabular}{|c|c|c|c|c|c|}
\hline \multirow{2}{*}{ Temp. } & \multicolumn{5}{|c|}{ Viscosities. } \\
\hline & 1 per cent. & 5 per cent. & 10 per cent. & 20 per cent. & to per cent. \\
\hline $0 .$. & .01810 & .02048 & .02436 & .03720 & $\cdot 1476$ \\
\hline $5 \ldots$ & 01537 & .01729 & .02050 & .03042 & $\cdot 1133$ \\
\hline $10 \ldots$. & $\cdot 01331$ & $\cdot 01488$ & 01754 & $\cdot 02578$ & .0895 \\
\hline $15 \ldots \ldots \ldots$ & .01168 & .01292 & .01518 & .02212 & .0730 \\
\hline $20 \ldots \ldots \ldots$ & .01031 & .01139 & .01328 & .01910 & .0607 \\
\hline $25 \ldots \ldots \ldots$ & $\cdot 00931$ & .01009 & .01173 & .01674 & .0508 \\
\hline $30 \ldots \ldots \ldots$ & .00812 & .00901 & .01041 & .01485 & .04233 \\
\hline $35 \ldots$ & .00737 & .00809 & $\cdot 00933$ & .01319 & .03618 \\
\hline $40 \ldots$ & .00670 & .00732 & .00843 & .01180 & .03132 \\
\hline $45 \ldots$. & .00609 & $\cdot 00668$ & .00763 & 01059 & .02728 \\
\hline $50 \ldots \ldots \ldots$ & .00555 & 00611 & .00699 & .00961 & .02410 \\
\hline $55 \ldots \ldots$ & 00511 & .00564 & .00640 & 00872 & .02140 \\
\hline $60 \ldots$ & .00473 & .00521 & .00592 & .00799 & .01908 \\
\hline 65 & $\cdot 00438$ & .00487 & .00549 & .00732 & $\cdot 01722$ \\
\hline $70 \ldots$ & $\cdot 00410$ & .00455 & .00512 & .00676 & .01563 \\
\hline $75 \ldots$ & .00387 & .00427 & .00480 & .00629 & 01414 \\
\hline $80 \ldots \ldots$. & $\cdot 00362$ & $\cdot 00399$ & .06448 & .00586 & .01288 \\
\hline $85 \ldots \ldots$ & .00340 & $\cdot 00377$ & 00421 & .00548 & $\cdot 01182$ \\
\hline $90 \ldots \ldots$ & .00320 & $\cdot 00349$ & .00389 & .00511 & .01093 \\
\hline
\end{tabular}

My best thanks for valuable advice and direction are due to T. R. Lyle, M.A., Professor of Natural Philosophy, E. F. J. Love, M.A., F.R.A.S., Demonstrator and Assistant Lecturer in Natural Philosophy, D. Orme Masson, M.A., D.Sc., F.R.S.E., Professor of Chemistry, and to J. M. Baldwin, B.A., who plotted the curves with a considerable amount of care and painstaking.

Physical Laboratory,

Melbourne University,

Dec. 11, 1899.

XXIII. On the Thermal Conductivities of Mixtures and of their Constituents. By Charles H. Lafes, D.Sc.*

THOSE physicists who have endeavoured to express the 1 thermal conductivities of physical mixtures in terms of the conductivities of their constituents, and the amount of each present, have made use of the formulæ

* Communicated by the Physical Society : read November 24, 1899. 